\title{
Doing Good by Doing Bad: How Tone at the Top and Tone at the Bottom Impact Performance-Improving Noncompliant Behavior
}

\author{
Corinna Ewelt-Knauer ${ }^{1} \cdot$ Anja Schwering ${ }^{2}\left[\right.$ (1) $\cdot$ Sandra Winkelmann ${ }^{1}(1)$
}

Received: 30 October 2019 / Accepted: 6 October 2020 / Published online: 22 October 2020

(c) The Author(s) 2020

\begin{abstract}
This study investigates how tone at the top, implemented by top management, and tone at the bottom, in an employee's immediate work environment, determine noncompliance. We focus on the disallowed actions of employees that improve their own and, in turn, the company's performance, referred to as performance-improving noncompliant behavior (PINC behavior). We conduct a survey of German sales employees to investigate specifically how, on the one hand, (1) corporate rules and (2) performance pressure, both implemented by top management, and, on the other hand, (3) others' PINC expectations and (4) others' PINC behavior, both arising from the employee's immediate work environment, influence PINC behavior. When considered in isolation, we find that corporate rules, as top management's main instrument to guide employee behavior, decrease employee PINC behavior. However, this effect is negatively influenced by the employees' immediate work environment when employees are expected to engage in PINC or when others engage in PINC. In contrast, even though top management places great performance pressure on employees, that by itself does not increase PINC behavior. Overall, our study informs practitioners and researchers about whether and how the four determinants increase or decrease employees' PINC behavior, which is important to comprehend triggers and to counteract such misconduct.
\end{abstract}

Keywords Noncompliance - Tone at the top · Tone at the bottom · Corporate rules · Performance pressure - Others' expectations · Others' behavior

\section{Introduction}

A large number of corporate scandals, such as those of Enron, Xerox, and Volkswagen, have attracted public attention, resulting in enormous negative legal and reputational consequences (Bergstresser and Philippon 2006; Sims and

Electronic supplementary material The online version of this article (https://doi.org/10.1007/s10551-020-04647-6) contains supplementary material, which is available to authorized users.

Sandra Winkelmann

sandra.winkelmann@wirtschaft.uni-giessen.de

Corinna Ewelt-Knauer

corinna.ewelt-knauer@wirtschaft.uni-giessen.de

Anja Schwering

anja.schwering@uni-potsdam.de

1 Justus-Liebig-University Gießen (Germany), Licher Straße 62, 35394 Gießen, Germany

2 University of Potsdam (Germany), August-Bebel-Str. 89, 14482 Potsdam, Germany
Brinkmann 2003). These scandals all involve noncompliant behavior of corporate employees. Noncompliance occurs when employees deviate from the rules, whether the law, regulations, or firm-specific rules (Ewelt-Knauer et al. 2020; Weber and Wasieleski 2013). Employees behave in a noncompliant manner for diverse reasons. Umphress and Bingham (2011) distinguish three boundary conditions: (1) noncompliant behavior without specific intention, (2) noncompliant behavior to benefit the organization, and (3) noncompliant behavior to benefit oneself. Whereas traditional research primarily focuses on self-interested noncompliance, studies have started to investigate noncompliant behavior aimed to support one's organization, for example, by withholding or misrepresenting information that would harm the company (Dahling et al. 2012; Mahlendorf et al. 2018; Umphress and Bingham 2011; Umphress et al. 2010).

This study adds to this research but focuses on performance-improving noncompliant behavior (PINC behavior), ${ }^{1}$

\footnotetext{
${ }^{1}$ For reading convenience, we use performance-improving noncompliance (PINC) as a synonym.
} 
which is a hybrid type, since it is beneficial to both the individual and the organization. In detail, by being noncompliant, the employee not only improves his or her own performance, but also the performance of the entire organization (Morrison 2006). Consequently, if the organization also profits from PINC, employees can more easily justify their PINC behavior morally, because they can interpret the rule violation as desirable from the company's perspective as well. PINC behavior is especially crucial in sales departments since sales employees are mainly responsible for generating the firm's revenues and typically have high, competitive performance goals (Badrinarayanan et al. 2019; Román and Ruiz 2005; Serviere-Munoz and Mallin 2013). For instance, a sales employee can be noncompliant if a product is sold to customers who are unauthorized due to their regional location or specific customer characteristics. For example, a noncompliant sales employee may sell weapons to customers in sanctioned regions or alcohol to children. This noncompliance improves the sales employee's own performance and generates revenue for the company, such that PINC behavior can lead to individual and organizational benefits, at least in the short run. However, it is immensely difficult for top management to prevent PINC and avoid its feared negative long-term consequences like reputational, legal and financial damage. Thus, to effectively prevent PINC behavior, it is crucial to understand what facilitates it, which is where our study contributes.

In detail, we examine how social norms, that is, injunctive norms (the expectations of others) and descriptive norms (the behavior of others), related to tone at the top and tone at the bottom, influence PINC behavior (Cialdini et al. 1990). Prior research shows that the tone at the top - top management's way to express (ethical) values pursued in the organization and provide guidance to employees-is an important predictor of ethical behavior (Warren et al. 2015). However, prior research also raises the question of how incongruences within tone at the top and between tone at the top and tone at the bottom influence employees' misbehavior (Pickerd et al. 2015). Regarding tone at the top, two injunctive norms are particularly important to convey compliance expectations from the top to individual employees: (1) corporate rules of conduct and (2) incentive schemes to stimulate employee performance (Fleischman et al. 2019; Tyler and Blader 2005; Warren et al. 2015; Weaver et al. 1999). Corporate rules are a formalized framework directly expressing which behaviors are right and wrong in top management's eyes, representing a company's superior injunctive norm (Tyler and Blader 2005). Further, incentive schemes and the resulting performance pressure indirectly address how top management balances the potential conflict of being compliant, on the one hand, and financially successful, on the other hand. Studies show that when performance pressure is high, top management creates an aggressive performance culture through incentive systems (Pickerd et al. 2015), influencing employee behavior such as noncompliance (Barsky 2008; Ordóñez and Welsh 2015; Ross and Robertsin 2003; Welsh et al. 2019).

In contrast, tone at the bottom describes values conveyed by the immediate work environment. Prior research has stressed that the (1) expectations of others (as an injunctive norm) and (2) behavior of others (as a descriptive norm) in the immediate environment strongly affect individual employee behavior (Ewelt-Knauer et al. 2020; Felps et al. 2006; Lord and DeZoort 2001; Warren et al. 2015).

We add to this research and not just research the main effects of PINC determinants, but also analyze moderating effects, i.e., how the effect of the tone at the top is influenced by the (incongruent) tone at the bottom. We thereby choose corporate rules as a benchmark, since they are an organizations' superior injunctive norm and the central means to communicate compliance values by top management (Tyler and Blader 2005; Weaver and Treviño 1999; Weaver et al. 1999). Beyond these clearly defined rules, we investigate whether performance pressure, others' expectations, and others' PINC behaviors moderate the expected PINC-decreasing effect of corporate rules.

Our survey results indicate that corporate rules generally decrease PINC. In contrast, others' PINC expectations and others' PINC behavior increase an individual's PINC behavior. Interestingly, the effect of corporate rules on PINC is moderated by the tone at the bottom, i.e., others' PINC expectations and others' PINC behavior. Hence, our findings indicate that corporate rules guide behavior, but only as long as there are no conflicting signals from the tone at the bottom. In contrast, we find that performance pressure itself has no direct main effect on PINC. Moreover, we find corporate rules still reduce the likelihood of PINC, even under high-performance pressure. Thus, high-performance pressure does not seem to encourage individuals to rationalize noncompliance when clear rules are in place.

Our main contributions to theory and practice are as follows. First, we add to the emerging stream of literature that considers pro-organizational noncompliance (Mahlendorf et al. 2018). However, in distinction to prior research, we investigate a hybrid type of noncompliant behavior that benefits the individual, as well as the organization. Hence, we consider situations in which incentives to be noncompliant are particularly strong and facilitate moral justification, since the PINC behavior is mutually beneficial. Second, as suggested by Badrinarayanan et al. (2019) and Fleischman et al. (2019), we not only include one determinant in our model but also simultaneously investigate the role of several determinants of (non)compliance. This leaves room for investigating the effect of incongruences between social norms related to different organizational levels' respective tones on ethical behavior (Pickerd et al. 2015). Third, our findings are highly 
interesting for practice, because we stress the importance of harmonious tone within firms and elaborate what determines the PINC behavior of employees and which determinants have a particularly strong effect compared to others. This facilitates a better understanding and, therefore, ability to counteract PINC behavior.

\section{Social Norms and Moral Decision-Making}

According to Cialdini and Trost (1998), social norms explain human behavior through social influences in the environment. They are particularly relevant when individuals face a moral dilemma, for instance, when they need to decide whether to engage in PINC behavior. Cialdini and Trost (1998) differentiate two types of social norms, injunctive and descriptive norms. Injunctive norms refer to rules or beliefs constituting which behaviors are (morally) approved and expected, and they lead to social rewards if one conforms with them, and social sanctions otherwise. They include management's expectations, in the form of corporate rules and performance pressure, as well as expectations from the immediate work environment. Descriptive norms show what behavior is normal in one's environment, like colleagues' or superiors' behavior, which serves as an indication of which actions will likely be effective.

Although a wide range of injunctive and descriptive norms are acting simultaneously in organizations, they do not influence employee behavior uniformly (Cialdini and Trost 1998). In fact, norms must be (1) internalized and (2) activated by the respective circumstances in a specific situation. First, according to self-concept maintenance theory, norms must be internalized to generally guide an individual's behavior. Only if internalized can they serve as a reference point to evaluate which behaviors are right and wrong, eliciting the desire to follow the right behavior to maintain a positive self-concept. Otherwise, when behaving contrary to internalized standards, individuals experience negative effects on their self-concept (Bandura 2002). However, ego-defensive mechanisms arise to avoid the negative effects on self-concept when norms are not followed (Bandura 2002; Bersoff 1999). One of these mechanisms is moral justification, which describes how individuals try to cognitively reframe their behavior as socially or morally meaningful to maintain a positive self-concept. When transferred to PINC behavior, moral justification could be based on that fact that (at least in the short term) the organization also benefits from the noncompliant behavior. Second, to guide behavior, (internalized) social norms must be activated in a specific situation. Especially in situations with incongruent norms, the norm that mainly directs an individual's behavior and is important to manage one's self-concept depends on the strength, immediacy, and number of people following the norm (Cialdini and Trost 1998; Cialdini et al. 1990).

\section{Hypotheses}

\section{Main Effects}

\section{Tone at the Top: Corporate Rules (H1) and Performance Pressure $(\mathrm{H} 2)$}

Prior research shows that corporate rules of conduct are the core of compliance values and, therefore, an organization's direct injunctive norm that directly guides how employees experience top management's compliance expectations (March et al. 2000; Tyler and Blader 2005; Weaver et al. 1999). They define what constitutes (non)compliance and act as an institutionalized, formally enforced injunctive norm, which means that employees must face organizational sanctions if they are caught in violation (Morrison 2006). However, Schaubroeck et al. (2012) show that the values conveyed by the company's top management are not necessarily adopted. First, employees must internalize corporate rules, because, according to moral disengagement theory, only adopted moral standards regulate an individual's behavior (Bandura 1999, 2002; Bandura et al. 1996). Second, the rules must be activated in a specific situation and perceived as important (Cialdini and Goldstein 2004). If both are the case, top management's explicit statement that such noncompliance is not accepted but sanctioned invalidates the argument of noncompliance only for the sake of helping the company. Hence, in conformance with prior research, we predict that deviations from corporate rules cause a negative update of one's self-concept, decreasing noncompliance.

Hypothesis 1 The presence of corporate rules is negatively related to PINC.

Compared to the direct message of corporate rules, performance pressure functions as an indirect injunctive norm of top management's expectations on compliance. To influence PINC behavior, again, the injunctive norm must be internalized and activated and therefore be salient in a specific situation (Cialdini et al. 1990). Thus, a high level of performance pressure strongly supports the impression that top management is more interested in financial success and less in following the rules. Since sales employees are continuously subject to a competitive environment with strong financial incentives, performance pressure should be omnipresent in a sales environment and therefore affecting behavior (Román and Ruiz 2005; Serviere-Munoz and Mallin 2013). Further, if employees perceive their performance targets as hardly achievable, 
they will probably consider PINC as a means of meeting management's expectations, facilitating moral disengagement. Specifically, if high-performance pressure is equated with top management's preference for financial success at the expense of compliance, individuals can cognitively reframe and morally justify their engagement in PINC behavior. Various studies also show that performance pressure-depending on the strength-can elicit unintended consequences, such as noncompliance (Barsky 2008; Fleischman et al. 2019; Ordóñez and Welsh 2015; Welsh et al. 2019), and can draw employee's attention to a mere goal pursuit while neglecting moral standards (Barsky 2008). We therefore hypothesize that performance pressure increases PINC, as follows.

Hypothesis 2 Performance pressure is positively related to PINC.

\section{Tone at the Bottom: Others' PINC Expectations (H3) and Others' PINC Behavior $(\mathrm{H} 4)$}

Besides social norms from the top, employees daily receive signals concerning compliance from their immediate work environment and, therefore, the tone at the bottom. These can affect behavior as an injunctive norm or a descriptive norm (Cialdini et al. 1990).

First, individuals can deduce whether PINC is expected of them, which is an injunctive norm influencing their behavior. Since the individual is directly confronted with the expectations of immediate colleagues or superiors, this norm should become internalized and activated (Cialdini et al. 1990). Further, the social sanctions on individuals deviating from the norm are directly tangible, so that they will have a strong tendency to meet the expectations of others in their immediate environment (Tepper 2010). Consistent with these findings, several studies show that employees especially strive to meet the expectations of their direct superiors, for example, to avoid disapproval or to increase their chances of being promoted (Bicchieri and Xiao 2009; Davis and Rothstein 2006). Hence, if a superior or colleagues in the immediate work environment expect PINC behavior, employees will likely try to meet expectations and engage in PINC. Employees can thereby morally justify their misconduct by diffusing responsibilities, since they only behaved in a noncompliant manner to fulfill the expectations of other firm members. Thus, employees can neutralize pressure to behave according to their moral standards (Barsky 2008). Consequently, we hypothesize that the behavioral expectations of noncompliance should also increase PINC.

Hypothesis 3 Others' expectations to engage in PINC are positively related to PINC.
Second, additional to these expectations, descriptive norms provide information, which actions are typical in a particular situation or environment (Cialdini et al. 1990), which we consider to be others' PINC behavior. We predict that individuals especially orient their actions toward those of people in their immediate work environment, that is, colleagues and superiors, since their behavior is particularly salient and proximal (Cialdini and Trost 1998). If other employees and superiors act noncompliant to improve, for example, their sales performance, employees will analyze whether this behavior is beneficial and follow it if it is (Bandura 1977). Further, concerning an individual's self-concept, the behavior of others often serves as a moral justification for one's own (PINC) behavior. In particular, in a business context, employees use the excuse that "everyone is doing it" to morally disengage from noncompliant actions (Barsky 2008; Green 1991). Hence, we predict that the descriptive norm of others' PINC behavior has an effect on the individual's decision to be noncompliant. Specifically, we hypothesize that, when an individual employee experiences strong PINC behavior in the immediate work environment, the employee is also more likely to engage in PINC.

Hypothesis 4 PINC behavior of others is positively related to PINC.

\section{Moderating Effects}

\section{Corporate Rules and (1) Performance Pressure (H5a), (2) Others' PINC Expectations (H5b), and (3) Others' PINC Behavior (H5c)}

Employees recurrently face situations in their organizations in which different social norms are acting simultaneously. These norms are often mutually incongruent, leading to a competition in which a situational signal activates one social norm over the other (Cialdini and Trost 1998). Depending on the strength (salience, tangibility, credibility, power), immediacy (proximity to the individual), and the number of people following, one norm will ultimately dominate the others and become the main influence on behavior. Beyond this background, we investigate whether and how norm incongruences within and between tones influence employees' PINC behavior. In particular, we examine whether and how the PINC-reducing effect of the superior injunctive norm of formally issued corporate rules is moderated by the PINCincreasing effect of (1) performance pressure, (2) others' PINC expectations, and (3) others' PINC behavior.

First, we analyze incongruences between injunctive norms within tone at the top and investigate whether performance pressure outweighs the effect of corporate rules on PINC behavior. Since both norms relate to top management, we do not expect differences concerning the immediacy, 
that is, the perceived proximity to both norms. However, we do expect differences concerning their strength, especially their salience. As mentioned, corporate rules explicitly state which behavior top management expects. In contrast, performance pressure is related to high, competitive performance goals (Serviere-Munoz and Mallin 2013), but could convey top management's expectation to engage in PINC only indirectly and implicitly. Hence, we predict that the social norm of corporate rules overrides performance pressure, since the former involves more strength and, especially, is more salient and more directly tangible, also concerning potential sanctions. Additionally, Stevens (2008) states that corporate rules are likely to be successful when they are embedded in the culture and perceived as credible and important, even when performance pressure is high. Further, clear corporate rules stating that noncompliance will not be tolerated discourage employees from moral disengagement. This reasoning is also supported by Welsh and Ordóñez (2014), who show that an individual's increased awareness of moral standards reduces noncompliance, even if difficult performance goals are given that previously induced high levels of noncompliance. In sum, we hypothesize that performance pressure does not moderate the PINC-reducing effect of corporate rules.

Hypothesis 5a Performance pressure does not moderate the negative effect of corporate rules on PINC.

Second, we want to analyze how incongruences between tones, that is, conflicting norms between the tone at the top and the tone at the bottom, influence PINC behavior. Specifically, we examine whether the expectations of others and their behavior in the immediate work environment moderate the effect of corporate rules defined by top management on PINC.

When superiors and colleagues in the immediate work environment expect PINC and/or engage in PINC, both of these social norms related to the tone at the bottom should be more proximal and present (immediacy) and more salient (strength) to the employee than the corporate rules stated by top management and therefore related to the tone at the top (Cialdini and Trost 1998). Further, social sanctions in the case of deviations from social norms should be perceived as more severe if they stem from persons in the immediate work environment. According to theory on social norms, these effects are even intensified the higher the number of people (both superiors and colleagues) expecting PINC or engaging in such conduct (Cialdini et al. 1990; Cialdini and Trost 1998). Meanwhile, the influence of the injunctive norm of corporate rules is undermined, since actual PINC expectations/behavior can hardly be reconciled with the credibility of corporate rules. The resulting detachment from corporate rules further facilitates moral justification, since individuals can reframe PINC as behaving as expected or behaving like everyone else (Barsky 2008; Green 1991). Therefore, we predict that corporate rules are perceived as subordinate and irrelevant, which downgrades the injunctive norm of corporate rules and, respectively, activates and prioritizes the injunctive norm of others' expectations or the descriptive norm of others' behaviors. Put differently, individuals will be very unlikely to attach great importance to corporate rules and will rather follow the (PINC) expectations and behavior of others in their immediate work environment. Hence, we predict that the PINC expectations and PINC behavior of others moderate the effect of corporate rules on PINC behavior.

Hypothesis 5b Others' PINC expectations moderate the negative effect of corporate rules on PINC such that corporate rules reduce PINC lesser when others' PINC expectations are high.

Hypothesis 5c Others' PINC behavior moderates the negative effect of corporate rules on PINC such that corporate rules reduce PINC lesser when others' PINC behavior is high.

\section{Method}

\section{Study Design and Sample}

We conducted a survey among German sales employees from November to December 2018. Sales employees are particularly appropriate for testing our predictions, since they are exposed to high, competitive goals of sales success (Román and Ruiz 2005; Serviere-Munoz and Mallin 2013). This should increase their tendency to behave in a noncompliant manner to increase their own and the company's performance, representing PINC behavior. Additionally, the working activities of sales employees are fairly homogeneous for different branches, which facilitate the operationalization of PINC and increases the comparability of the results. Hence, these conditions form a solid basis for the investigation of employees' PINC behavior.

Due to the sensitivity of our questions, we aimed to directly address the sales employees regarding their deviations from the rules or the PINC of superiors and colleagues. Therefore, potential subjects were mainly 
recruited by distributing our survey on Facebook, XING, ${ }^{2}$ and LinkedIn groups (e.g., the group Distribution \& Sales) to contact sales employees directly. To answer the questionnaire, participants received fixed compensation in the amount of $€ 10.00$. In total, we received 171 responses. Two respondents stated that they did not work in sales and 78 did not completely answer all of our questions of interest, ${ }^{3}$ and these respondents were excluded from the sample. Our final sample thus comprises 93 responses.

Concerning the characteristics of our sample, the respondents were, on average, 30 to 39 years old and $77.42 \%$ were male, which is consistent with the sales professions having been dominated by men for many years. Approximately one-third of the respondents $(34.41 \%)$ had been with their current employer from one to three years, while almost half $(47.31 \%)$ reported having more than three years of work experience. With regard to the respondents' position in the company, $49.46 \%$ worked at lower hierarchical levels as a customer consultant or seller. The company sizes varied, with more than one-third of the respondents having stated that the number of employees at their company was below 100 and approximately one-quarter $(23.66 \%)$ reporting over 3,000 employees. In sum, our sample represents a cross section of sales employees in terms of work experience, position, and company size that is comparable to those of other sales surveys from Germany or Europe, indicating that the sample is a representative one (Anlanger et al. 2015; Deloitte 2019; Román et al. 2018; Schmitz 2013).

Besides, we tested for non-response bias. The test is based on the assumption that late respondents and non-respondents are structurally similar; that is, a comparison of early and late respondents should reveal a potential non-response bias (Arnold and Artz 2015). We performed two-sample t-tests to check for differences in the hypothesized variables between the first and last thirds of the questionnaires received. Since we do not find any significant differences (with all $p$-values $>0.1$, two tailed), we infer that a potential non-response bias is unlikely, mitigating the concern that our sample is not representative (Armstrong and Overton 1977).

\section{Dependent Variable}

We use multiple items to measure our variables, since we investigate constructs that are not directly observable (Gorsuch 1997; Spector 1992). For most items, the participants had to assess statements on a seven-point Likert-scale, with

\footnotetext{
${ }^{2}$ XING is a social network similar to LinkedIn that is widespread throughout Western Europe. XING members manage their professional contacts and organize themselves by interest groups.

3 The participants had the option to not answer individual questions. This reduced our final sample but increased the truthfulness of the information provided.
}

one for strongly disagree and seven for strongly agree (see the Appendix). To reduce response bias, we phrased some items negatively.

To capture our dependent variable, which is individuals' engagement in PINC (PINC), we use self-developed items, for two reasons. First, until now, only a few studies have investigated constructs generally comparable to PINC behavior (Mahlendorf et al. 2018). One established construct is (the willingness to engage in) pro-organizational unethical behavior ((W)UPB), ${ }^{4}$ developed by Umphress et al. (2010), which concentrates on unethical behavior for the company's benefit. With PINC, instead, we focus on performance increases that are beneficial for both the individual and the organization. Thus, we use (W)UPB as a starting point, but transfer it to the context of PINC. Second, we focus on a specific setting, namely, a sales setting, which is characterized by a strong conflict of objectives between sales success and compliance (Román and Ruiz 2005; Serviere-Munoz and Mallin 2013), which we also integrate when developing the items. Beyond this background and in distinction from (W)UPB, we state more concrete reasons for an individual's PINC in our items. For instance, instead of using more general reasons such as helping/benefitting the organization (Mahlendorf et al. 2018; Umphress et al. 2010), we relate elements of PINC to more specific reasons such as increasing company success, sales success, and achieving sales goals.

Overall, we use seven items to measure PINC behavior: five formulated as a general statement and two illustrative case studies that describe a specific sales situation involving a trade-off between customer needs and financial success. Essentially, all the items asked whether the participants would approve deviating from the rules in general or in specific situations, for example, if performance goals could only be achieved that way. Finally, we conduct principal component analysis (PCA), ${ }^{5}$ considering the relations that naturally arise between these items (Table 1). We retain one factor with a meaningful eigenvalue larger than one. Six of the seven items strongly load on this factor, revealing an overall Kaiser-Meyer-Olkin (KMO) measure of sampling adequacy of 0.82, which is sufficient (Kaiser 1960).

\footnotetext{
${ }^{4}$ Although the labeling differs, WUPB and UPB are measured and constructed based on the same survey items and are therefore identical (Mahlendorf et al. 2018; Umphress et al. 2010).

5 PCA reveals the distance/relatedness between items for a specific dataset. Factor loadings are therefore used as a weighting scheme to compile different factors that are linearly uncorrelated and thus offer different explanatory content (Bannier et al. 2020).
} 
Table 1 Descriptive Statistics and Factors from Principal Component Analysis

\begin{tabular}{|c|c|c|c|c|}
\hline \multicolumn{3}{|c|}{ Dependent variable } & \multicolumn{2}{|l|}{$\begin{array}{l}\text { Factor } 1 \\
\text { PINC }\end{array}$} \\
\hline Item & Mean & SD & \multicolumn{2}{|l|}{ Factor loading } \\
\hline PINCl & 3.839 & 1.617 & \multicolumn{2}{|l|}{0.847} \\
\hline PINC2 & 3.656 & 1.723 & \multicolumn{2}{|l|}{0.840} \\
\hline PINC3 & 4.075 & 1.752 & \multicolumn{2}{|l|}{0.776} \\
\hline PINC4 & 3.796 & 1.698 & \multicolumn{2}{|l|}{0.818} \\
\hline PINC5 & 4.032 & 1.463 & \multicolumn{2}{|l|}{0.569} \\
\hline PINC6 & 3.871 & 1.941 & \multicolumn{2}{|l|}{0.535} \\
\hline PINC7 & 2.602 & 1.695 & \multicolumn{2}{|l|}{0.346} \\
\hline \multicolumn{3}{|c|}{ Independent Variables: Tone at the Top } & $\begin{array}{l}\text { Factor } 2 \\
\text { RULES }\end{array}$ & $\begin{array}{l}\text { Factor } 3 \\
\text { PESS }\end{array}$ \\
\hline Item & Mean & $\mathrm{SD}$ & Factor Loading & Factor Loading \\
\hline$I N C 1$ & 3.979 & 1.588 & -0.141 & 0.671 \\
\hline$I N C 2$ & 4.049 & 1.331 & -0.076 & 0.708 \\
\hline INC3 & 3.602 & 1.669 & -0.106 & 0.802 \\
\hline INC4 & 3.656 & 1.844 & -0.056 & 0.489 \\
\hline RULES1 & 1.516 & 0.716 & -0.231 & 0.103 \\
\hline RULES2 & 5.323 & 1.650 & 0.753 & -0.094 \\
\hline RULES3 & 5.376 & 1.375 & 0.584 & -0.343 \\
\hline RULES4 & 4.516 & 1.761 & 0.195 & -0.488 \\
\hline RULES5 & 4.054 & 1.908 & 0.465 & -0.391 \\
\hline$A C C 1$ & 5.409 & 1.369 & 0.866 & -0.027 \\
\hline$A C C 2$ & 5.344 & 1.379 & 0.770 & -0.112 \\
\hline ACC3 & 5.860 & 1.419 & 0.499 & -0.173 \\
\hline$A C C 4^{*}$ & 0.602 & 0.492 & 0.331 & -0.276 \\
\hline$A C C 5^{*}$ & 0.623 & 0.487 & 0.225 & -0.312 \\
\hline \multicolumn{3}{|c|}{ Independent Variables: Tone at the Bottom } & $\begin{array}{l}\text { Factor } 4 \\
\text { EXPECT }\end{array}$ & $\begin{array}{l}\text { Factor } 5 \\
B E H A V\end{array}$ \\
\hline Item & Mean & SD & Factor Loading & Factor Loading \\
\hline SUPER1 & 2.914 & 1.516 & 0.137 & 0.528 \\
\hline SUPER2 & 4.387 & 1.776 & 0.154 & 0.745 \\
\hline SUPER3 & 3.742 & 1.693 & 0.228 & 0.766 \\
\hline SUPER4 & 4.516 & 1.508 & 0.619 & 0.262 \\
\hline SUPER5 & 3.903 & 1.460 & 0.757 & 0.164 \\
\hline SUPER6 & 3.409 & 1.603 & 0.652 & 0.150 \\
\hline SUPER7 & 3.785 & 1.661 & 0.324 & 0.634 \\
\hline COLL1 & 5.075 & 1.484 & 0.072 & 0.787 \\
\hline COLL2 & 4.656 & 1.605 & 0.279 & 0.659 \\
\hline \multicolumn{3}{|c|}{ Control Variable } & \multicolumn{2}{|l|}{$\begin{array}{l}\text { Factor } 6 \\
\text { UTIL }\end{array}$} \\
\hline Item & Mean & $\mathrm{SD}$ & \multicolumn{2}{|l|}{ Factor Loading } \\
\hline UTIL1 & 2.624 & 1.560 & \multicolumn{2}{|l|}{0.602} \\
\hline UTIL2 & 2.957 & 1.841 & \multicolumn{2}{|l|}{0.790} \\
\hline UTIL3 & 3.280 & 1.930 & \multicolumn{2}{|l|}{0.752} \\
\hline UTIL4 & 3.172 & 1.672 & \multicolumn{2}{|l|}{0.753} \\
\hline
\end{tabular}

This table presents the factor loadings for the six factors with Eigenvalue $>1$, KMO criteria $>0.5$ and a Cronbach alpha $>0.7$. For each factor resulting from principal component analysis, we consider those items with factor loadings $>(+/-) 0.4$ (marked in bold) according to Hair et al. (2019). Multiple items were used to measure performance-increasing noncompliance (PINC1-7), incentives (INC1-4), corporate rules (RULES15 ) and their acceptance (ACC1-5), superior's expectations and behavior (SUPER1-7), colleagues' behavior (COLL1-2) and individual's utilitarianism (UTIL1-4). Most Items are measured on a seven-point Likert-scale with 1 for strongly disagree and 7 for strongly agree, few items $($ marked with $*$ ) differ. For the respective items and scales, see Appendix 
Table 1 (continued)

Variables are defined as follow: PINC Individuals' engagement in performance-improving noncompliance (PINC), RULES Corporate rules and their communication and credibility, PRESS Perceived performance pressure, EXPECT Others' expectations to engage in PINC in the immediate work environment, BEHAV Others' PINC behavior in the immediate work environment, UTIL An individual's tendency to harm for the greater good

\section{Independent and Control Variables}

To operationalize our independent variables, we asked several questions related to tone at the top and tone at the bottom (see the Appendix). We again use PCA to determine which item refers to our four independent variables of interest. PCA reveals two factors, respectively, for tone at the top (Factor 2, corporate rules; Factor 3, performance pressure) and for the tone at the bottom (factor 4, others' PINC expectations; Factor 5, others' PINC behavior), which are presented in Table 1 and described below.

In detail, the second factor loads strongly on almost all the items concerning the awareness, communication, and acceptance of corporate rules and therefore represents our variable for corporate rules (RULES). The third factor is characterized by a highly positive correlation with items involving high-performance goals and the difficulty of achieving these with or without compliance. Meanwhile, this factor is negatively correlated with the superior's tendency to report rule deviations. Hence, this factor represents our variable for performance pressure (PRESS).

With regard to tone at the bottom, the fourth factor loads heavily on those items that involve the superior's reactions to and judgment of PINC-related behavior and decisions, for instance, whether a superior (generally) expects PINC behavior or accepts forgoing a lucrative deal due to compliance issues. Therefore, this factor represents others' expectations of engagement in PINC (EXPECT). Finally, the fifth factor loads heavily on those items that consider the potential rule violations of others in the immediate work environment, which we summarize as others' PINC behavior (BEHAV).

For all the factors deduced from the PCA, we consider those items with factor loadings larger than 0.4 and use common thresholds for the factors of a meaningful eigenvalue larger than one, a Cronbach alpha above 0.7, and a KMO measure of sampling adequacy above 0.5 as the cutoffs (Hair et al. 2019; Kaiser 1960; Tabachnick and Fidell 2014).

Since individuals are expected to respond differently to the same environmental cues (Ross and Robertsin 2003), we further include an individual's characteristics as control variables. Specifically, we consider one factor that measures an individual's moral decision-making (UTIL). Therefore, we use the subscale of instrumental harm, which belongs to the Oxford Utilitarianism Scale, which consists of four items capturing the willingness to cause harm to achieve the greater good (Kahane et al. 2018)(Kahane et al. 2018). Additionally, we include the employee's gender (GENDER) and closeness to retirement (RETIRE) as control variables (Mahlendorf et al. 2018). At the company level, we further include the fit of the company's values with the individual's values (VALUES), the absence/presence of a compliance department (COMPL), and the number of employees in the company as a proxy for employer size (SIZE).

\section{Results}

While Table 1 presents the descriptive statistics per item, Table 2 displays the correlations of the independent variables. In a few cases, the correlation matrix reveals significant correlations between independent variables; however, these are far below 0.80 , indicating only a weak association and minimizing concerns of multicollinearity (Galbreath 2019; O'Brien 2007). Further, we compute the variance inflation factor after the regression analysis, which measures the severity of the multicollinearity. We find that RULES exhibits the highest variance inflation factor, 2.70, which is far below the critical value of five and is therefore also considered acceptable (Chatterjee and Hadi 2015).

With regard to our hypothesis testing, we test three models to ensure the robustness of our results (see Table 3 ). Model 1 does not include any control variables. In model 2 , we add the control variables that consider that an individual's characteristics are important in decision-making with regard to PINC. In model 3, we additionally include at the company level whether the individual's values match the company's values and whether a compliance department exists and control for company size.

Before running the three regressions, we first check for a normal distribution and homoscedasticity as requirements for the applicability of the regression analysis. Neither in the case of the Shapiro-Wilk $W$-test for a normal distribution nor in the case of White's test for heteroscedasticity is the null hypothesis rejected (all $p$-values $>0.1$ ). Hence, the results indicate support for all three models we include in our hypothesis testing. Further, the $R^{2}$ and adjusted $R^{2}$ values reveal a high level of model fit in all three models.

Table 3 presents the results of the regression analysis. Hypothesis 1 states that corporate rules are negatively related to PINC. Consistent with this finding, our results reveal a significant negative effect of corporate rules (RULES) on PINC behavior, supporting - in line with prior research $-\mathrm{H} 1$ ( $p=0.061$, two tailed). Hence, corporate rules 
Table 2 Correlation matrix

\begin{tabular}{|c|c|c|c|c|c|c|c|c|c|c|}
\hline & (1) & (2) & (3) & (4) & (5) & (6) & (7) & (8) & (9) & (10) \\
\hline (1) RULES & 1 & & & & & & & & & \\
\hline (2) PRESS & -0.02 & 1 & & & & & & & & \\
\hline (3) EXPECT & $-0.36^{* *}$ & 0.12 & 1 & & & & & & & \\
\hline (4) $B E H A V$ & $-0.60 * *$ & $0.24 *$ & 0.09 & 1 & & & & & & \\
\hline \multicolumn{11}{|l|}{ Controls: } \\
\hline (5) UTIL & -0.08 & -0.18 & 0.12 & 0.13 & 1 & & & & & \\
\hline (6) RETIRE & 0.03 & 0.12 & 0.01 & -0.07 & -0.16 & 1 & & & & \\
\hline (7) GENDER & -0.06 & 0.07 & 0.15 & -0.04 & -0.13 & 0.01 & 1 & & & \\
\hline (8) VALUES & $0.47 * *$ & -0.02 & -0.08 & $-0.29 * *$ & -0.18 & $0.24 *$ & -0.03 & 1 & & \\
\hline (9) $C O M P L$ & 0.11 & -0.06 & -0.05 & -0.04 & 0.07 & -0.10 & 0.04 & 0.05 & 1 & \\
\hline (10) SIZE & -0.03 & 0.01 & -0.02 & 0.01 & -0.09 & -0.12 & $0.26^{*}$ & $-0.21^{*}$ & -0.13 & 1 \\
\hline
\end{tabular}

This table presents Spearman correlation coefficients as in all cases at least one variable is non-binary $* p \leq 0.05 ; * * p \leq 0.01 ; n=93$

RULES corporate rules and their communication and credibility, PRESS perceived performance pressure, EXPECT others' expectations to engage in PINC in the immediate work environment, BEHAV others' PINC behavior in the immediate work environment, UTIL an individual's tendency to harm for the greater good, RETIRE an individual's closeness to retirement ( 1 if $>55$ life years, 0 otherwise), GENDER gender ( $1=$ male, $2=$ female, $3=$ no information), VALUES company values conform with personal values $(1=$ do not agree at all, $7=$ fully agree), $C O M P L$ independent compliance department in the company $(1=$ yes, $2=$ no, $3=I$ don't know), SIZE company size based on the number of employees $(1<=100 ; 2=100-300$; $3=300-1.000 ; 4=1.000-3.000 ; 5>=3.000 ; 6=$ no information)

not only are a theoretically important injunctive norm, but also have the power to guide behavior and reduce PINC.

Second, in contrast with and related to tone at the top, we predict that the injunctive norm of performance pressure (H2) increases an individual's tendency toward PINC behavior, describing a positive relation. The coefficients concerning performance pressure (PRESS) are, in fact, positive, but not significant. A possible explanation for this finding is that performance pressure can have two effects: employees can exert greater effort or they can engage in more rule violations to increase their performance, potentially leading to less clear results.

Third, with regard to social norms related to the tone at the bottom, H3 posits that the injunctive norm of others' expectations to engage in PINC also increases individual's PINC behavior, because individuals want to meet expectations, among other things, to avoid the social sanctions of the persons they want to impress. Our results indicate support for $\mathrm{H} 3$ and reveal a positive and significant association of PINC expectations (EXPECT) with the individual's PINC behavior ( $p=0.018$, two tailed).

Fourth, we predict in $\mathrm{H} 4$ that the descriptive norm of the actual PINC behavior of individuals in the immediate work environment (BEHAV) is positively related to PINC. Accordingly, the regression analysis strongly supports this prediction ( $p=0.006$, two tailed), indicating that PINC behavior, particularly in the immediate work environment, fosters an employee's engagement in PINC.
Besides these main effects, we test three moderating effects to consider incongruences between social norms within and between tones. Specifically, we investigate whether the PINCdecreasing effect of corporate rules as a superior injunctive norm and, therefore, benchmark for noncompliant behavior can be maintained when moderated by another competing social norm influencing PINC behavior. Hence, we are interested in whether the effect of within- or between-tone conflicts in social norms is positive or negative with regard to PINC.

Against this background, H5a refers to incongruent social norms within the tone at the top and predicts that the desired PINC-decreasing effect of corporate rules is not moderated by performance pressure. We argue that the injunctive norm of corporate rules has a more direct effect on employee behavior than that of the indirect injunctive norm of performance pressure, which is therefore overridden by the former. Even though our results reveal a significant interaction ( $p=0.042$, two tailed), the coefficient is still negative, showing that corporate rules still reduce PINC, even under performance pressure. Additionally, Fig. 1 reveals that strong corporate rules decrease PINC, despite performance pressure. The effect of corporate rules is slightly stronger when performance pressure is high.

In contrast, $\mathrm{H} 5 \mathrm{~b}$ and $\mathrm{H} 5 \mathrm{c}$, representing the incongruence of the social norms between tones, both predict that the negative effect of corporate rules on PINC is moderated by influences from the tone at the bottom. Specifically, H5b posits that corporate rules reduce PINC lesser when others' PINC expectations are high, which is also supported $(p=0.066$, two 
Table 3 Regression analysis

\begin{tabular}{|c|c|c|c|c|}
\hline Hypothesis (predicted sign) & Independent variables & $\begin{array}{l}\text { Model 1: } \\
\text { No control variables }\end{array}$ & $\begin{array}{l}\text { Model 2: } \\
\text { Control variables } \\
\text { Individual }\end{array}$ & $\begin{array}{l}\text { Model 3: } \\
\text { Control variables } \\
\text { Individual + Company }\end{array}$ \\
\hline \multicolumn{5}{|l|}{ Dependent variable $P I N C$} \\
\hline H1 (-) & RULES & $\begin{array}{l}-0.217 * \\
(0.061)\end{array}$ & $\begin{array}{l}-0.235^{* *} \\
(0.040)\end{array}$ & $\begin{array}{l}-0.290^{* *} \\
(0.025)\end{array}$ \\
\hline $\mathrm{H} 2(+)$ & PRESS & $\begin{array}{l}0.060 \\
(0.498)\end{array}$ & $\begin{array}{l}0.072 \\
(0.419)\end{array}$ & $\begin{array}{l}0.078 \\
(0.391)\end{array}$ \\
\hline $\mathrm{H} 3(+)$ & EXPECT & $\begin{array}{l}0.242 * * \\
(0.018)\end{array}$ & $\begin{array}{l}0.241 * * \\
(0.017)\end{array}$ & $\begin{array}{l}0.231 * * \\
(0.029)\end{array}$ \\
\hline $\mathrm{H} 4(+)$ & $B E H A V$ & $\begin{array}{l}0.328 * * * \\
(0.006)\end{array}$ & $\begin{array}{l}0.311^{* * * *} \\
(0.007)\end{array}$ & $\begin{array}{l}0.292 * * \\
(0.014)\end{array}$ \\
\hline H5a (-) & $R U L E S \times P R E S S$ & $\begin{array}{l}-0.219^{* *} \\
(0.042)\end{array}$ & $\begin{array}{l}-0.252 * * \\
(0.020)\end{array}$ & $\begin{array}{l}-0.254^{* *} \\
(0.022)\end{array}$ \\
\hline $\mathrm{H} 5 \mathrm{~b}(+)$ & $R U L E S \times E X P E C T$ & $\begin{array}{l}0.182 * \\
(0.066)\end{array}$ & $\begin{array}{l}0.177 * \\
(0.077)\end{array}$ & $\begin{array}{l}0.204 * * \\
(0.049)\end{array}$ \\
\hline \multirow[t]{7}{*}{$\mathrm{H} 5 \mathrm{c}(+)$} & $R U L E S \times B E H A V$ & $\begin{array}{l}0.219 * * \\
(0.015)\end{array}$ & $\begin{array}{l}0.178 * * \\
(0.050)\end{array}$ & $\begin{array}{l}0.166^{*} \\
(0.077)\end{array}$ \\
\hline & $U T I L$ & & $\begin{array}{l}0.156^{*} \\
(0.082)\end{array}$ & $\begin{array}{l}0.157 * \\
(0.085)\end{array}$ \\
\hline & RETIRE & & $\begin{array}{l}0.427 * \\
(0.087)\end{array}$ & $\begin{array}{l}0.444 * \\
(0.091)\end{array}$ \\
\hline & GENDER & & $\begin{array}{l}-0.162 \\
(0.302)\end{array}$ & $\begin{array}{l}-0.178 \\
(0.283)\end{array}$ \\
\hline & VALUES & & & $\begin{array}{l}0.035 \\
(0.502)\end{array}$ \\
\hline & $C O M P L$ & & & $\begin{array}{l}0.148 \\
(0.238)\end{array}$ \\
\hline & $S I Z E$ & & & $\begin{array}{l}0.014 \\
(0.761)\end{array}$ \\
\hline$R^{2}$ & & 0.480 & 0.519 & 0.526 \\
\hline Adjusted $R^{2}$ & & 0.437 & 0.461 & 0.448 \\
\hline$F$-Value & & $11.21^{* * * *}$ & $8.85^{* * *}$ & $6.67^{* * *}$ \\
\hline$n$ & & 93 & 93 & 92 \\
\hline
\end{tabular}

This table presents the results of the regressions with the dependent variable PINC. The values presented for model 1 to 3 indicate the regression coefficients, while the $\mathrm{p}$-values are in parentheses. All $p$-values are two tailed

$P I N C$ Individuals' engagement in performance-improving noncompliance (PINC), RULES Corporate rules and their communication and credibility, PRESS Perceived performance pressure, EXPECT Others' expectations to engage in PINC in the immediate work environment, BEHAV Others' PINC behavior in the immediate work environment, UTIL An individual's tendency to harm for the greater good, RETIRE An individual's closeness to retirement ( 1 if $>55$ life years, 0 otherwise), GENDER Gender ( $1=$ male, $2=$ female, $3=$ no information), VALUES Company values conform with personal values $(1=$ do not agree at all, $7=$ fully agree $), C O M P L$ Independent compliance department in the company ( $1=$ yes, $2=$ no, $3=$ I don't know), SIZE Company size based on the number of employees $(1<=100 ; 2=100-300 ; 3=300-1.000 ; 4=1.000-$ $3.000 ; 5>=3.000 ; 6=$ no information)

$* p \leq 0.1 ; * * p \leq 0.05$; *** $p \leq 0.01$

tailed). As depicted in Fig. 2, corporate rules reduce PINC more when others' PINC expectations are low compared to high. Similarly, H5c states that corporate rules reduce PINC lesser when others' PINC behavior is high. As predicted, we find support for this result and a significant positive effect on PINC ( $p=0.015$, two tailed). Accordingly, Fig. 3 shows that strong corporate rules can only reduce PINC substantially when others' PINC behavior is less pronounced. However, as shown in the results, as well as in Fig. 3, the moderating effect of others' PINC behavior is stronger than in the case of 
Fig. 1 Corporate Rules and Performance Pressure. Figure 1 presents the RULES $\times$ PRESS interaction for PINC (low/high defined as below/above the median). PINC Individuals' engagement in performanceimproving noncompliance. RULES Corporate rules and their communication and credibility. PRESS Perceived performance pressure
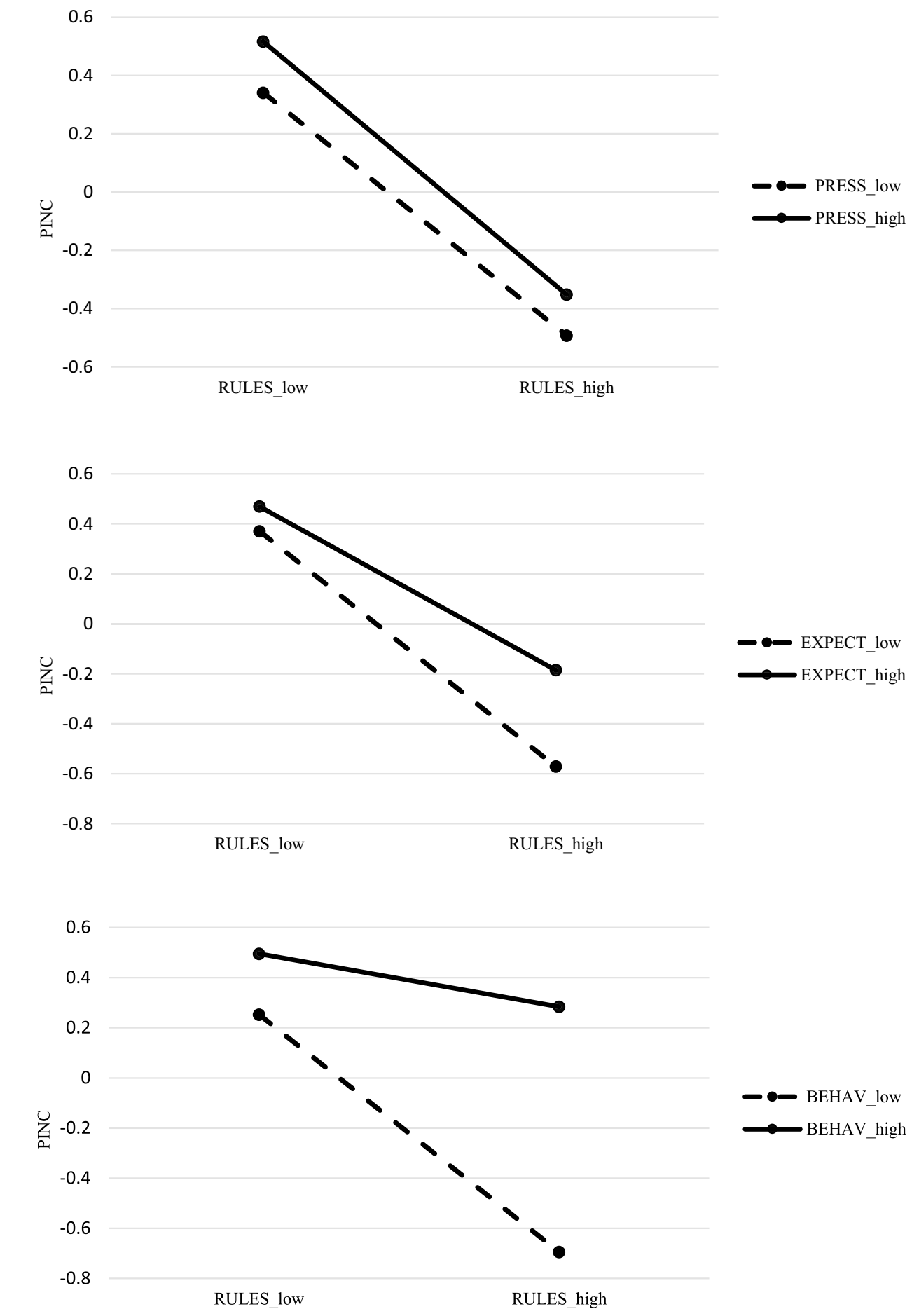

Fig. 2 Corporate Rules and Others' PINC Expectations. Figure 2 presents the RULES $\times$ EXPECT interaction for PINC (low/high defined as below/ above the median). PINC Individuals' engagement in performance-improving noncompliance. RULES Corporate rules and their communication and credibility. EXPECT Others' expectations to engage in PINC in the immediate work environment

Fig. 3 Corporate Rules and Others' PINC Behavior. Figure 3 presents the RULES $\times$ BEHAV interaction for PINC (low/high defined as below/ above the median). PINC Individuals' engagement in performance-improving noncompliance. RULES Corporate rules and their communication and credibility. BEHAV Others' PINC behavior in the immediate work environment other's PINC expectations, underlining the importance of the compliance behavior of employees in the immediate work environment. Overall, with regard to $\mathrm{H} 5 \mathrm{~b}$ and $\mathrm{H} 5 \mathrm{c}$, both social norms related to the tone at the bottom seem to undermine the credibility of corporate rules, weakening their influence, enabling moral justification, and fostering PINC. This result specifically highlights the importance of social norms related to tone at the bottom and their influence on PINC behavior, even if contrary values are conveyed by the company's top management. In sum, while incongruences within tone at the top with performance pressure do not necessarily lead to more PINC behavior, the promotion of an unethical tone at the bottom, which is the case when immediate superiors and colleagues expect PINC or engage in PINC, outweighs the decreasing effect of corporate rules. 
To ensure the robustness and validity of our results, we further run two regressions including control variables. ${ }^{6}$ In model 2 , we specifically consider control variables that relate to the individual, because individuals likely respond differently to the same stimuli (Ross and Robertsin 2003). Therefore, we include (1) UTIL as a factor measuring one's willingness to cause harm to bring about the greater good; (2) closeness to retirement (RETIRE), which can increase noncompliance; and (3) gender (GENDER). With regard to $\mathrm{H} 1$ to $\mathrm{H} 5 \mathrm{c}$, the results are inherently the same when these control variables are included. Further, the results indicate a significant positive effect of an individual's acceptance of harm for the greater good ( $p=0.082$, two tailed) and an individual's closeness to retirement ( $p=0.087$, two tailed). Additionally, in model 3 , the results are further supported when controlling for the respective company values (VALUES), the presence of a compliance department (COMPL), and company size (SIZE), which do not have a significant influence. However, the increases in $R^{2}$ values from model 1 to model 2 to model 3 also reflect improved model fit, further validating our results. Finally, after the regression analysis, we conduct a regression specification error test to ensure no model misspecifications through omitted variables. The results suggest that our models have no omitted variables and are correctly specified.

\section{Discussion and Conclusion}

Our study highlights how social norms related to the tone at the top and tone at the bottom impact PINC behavior. PINC behavior favors not only the employee but also the organization, by increasing the individual's as well as the organization's performance. Therefore, it is particularly difficult to overcome PINC behavior, since supporting the organization can morally justify misconduct, a cognitive mechanism to avoid negative effects on self-concept despite rule violations. However, at least in the long run, PINC can lead to enormous negative legal and reputational consequences (Bergstresser and Philippon 2006; Sims and Brinkmann 2003), which is why companies want to counteract such behavior.

Against this background, we shed light on what increases or decreases employees' PINC behavior. Since an organization's tone at the top and tone at the bottom are treated as important predictors of ethical or unethical behavior (Warren et al. 2015), we investigate the four most important social norms emanating from these tones, based on a survey among German sales employees. With regard to tone at the top, we consider two social norms that top management mainly uses to convey compliance values to employees. First, corporate

\footnotetext{
${ }^{6}$ We also use bootstrapping (with 1000 and 10.000 replications of our sample), rerun our models and find that our results mainly hold (not tabulated).
}

rules represent the core of the organization's compliance values, since they directly define (non)compliant behaviors and therefore guide employees' behavior and reduce PINC, consistent with our results. Second, performance pressure is more indirect but also important for conveying the expectations of top management to employees. However, our results do not indicate a significant effect of performance pressure on PINC. Besides these two main effects, we investigate whether performance pressure moderates the effect of corporate rules, representing incongruence between social norms within the tone at the top. We find that corporate rules still guide behavior as desired, even if performance pressure is high. Hence, an organization's emphasis on financial success in incentive systems does not necessarily rule out compliant behavior when top management credibly communicates corporate rules.

Further, to investigate how the tone at the bottom affects noncompliance, we examine how the two social norms of others' PINC expectations and others' PINC behavior in the immediate work environment influence behavior. We find that both others' expectations to engage in PINC and others' PINC behavior, respectively, increase one's PINC behavior. Further, regarding potential conflicts between tones, we find that the presence of other employees in the immediate environment expecting or engaging in PINC undermines the credibility of corporate rules so severely that individual employees are more likely to engage in PINC. Hence, the desired influence of corporate rules is moderated by impacts from the tone at the bottom, indicating a particularly strong effect of the direct work environment's tone at the bottom.

With these findings, our study contributes to both theory and practice. First, we combine the ethics literature with the organizational, psychological, and accounting literature. Second, compared to noncompliance for self-serving reasons, noncompliance that is at least beneficial for a company in the short term has not received much research attention (Mahlendorf et al. 2018). In distinction with prior research, we focus on PINC behavior as a hybrid type of noncompliance that helps to improve one's own as well as the organization's performance. Therefore, PINC behavior is a highly relevant issue that is particularly difficult to overcome, since mutual benefits can serve as moral justification. Third, we refer to Pickerd et al. (2015), who posit that it is important to better understand how employees respond to the tones at different organizational levels. Thus, our results underline the importance of harmonious tones, since conflicting values conveyed by the tone at the top and at the bottom raise the likelihood of PINC. Specifically, we can show that an unethical tone at the bottom strongly raises the potential for PINC behavior, even if the tone at the top conveys ethical values (Warren et al. 2015).

Additionally, our findings raise practitioner's awareness that PINC behavior is not desirable, even if it benefits the company in the short term. Specifically, we assist practitioners in understanding which social norms characterize 
the tone at the bottom, as well as the tone at the top, and how both influence noncompliant behavior. Essentially, our results underline the importance of clearly communicated corporate rules; however, when considering a broader organizational context, the results reveal that contradicting expectations and behaviors in an employee's immediate work environment can undermine the impact of corporate rules on behavior. Hence, to incentivize compliant instead of noncompliant behavior that improves both, the individual's and the organization's performance, it is important to create a work atmosphere characterized by social norms in the form of strong corporate rules as well as immediate superiors and colleagues who expect compliant behavior and actually behave compliantly. In this case, even high-performance pressure should not unfold detrimental effects on behavior, but can help to improve performance in a compliant way. Further, firms can stress that top performers actually followed the rules and can reward exceptionally high and at the same time compliant performances. Thereby, recognizing these performances makes it harder for the other employees to morally justify PINC, which should foster performance increases that are conform to corporate rules.

Naturally, our investigation is subject to limitations. First, the results should be interpreted with caution, since our sample size is rather small, probably due to the high sensitivity of the topic and potentially limited representative of the German sales population. However, for us, the findings are still worth adding to research on noncompliance that (also) benefits the organization, which is therefore particularly difficult to overcome. Second, we only consider sales employees, because the trade-off between success and compliance is particularly salient in a sales environment; however, future research could consider other areas to increase the generalizability of the results. Third, to get a more complete picture, it would be interesting to investigate the impacts of the tone in the middle resulting from values conveyed by middle management. Further, future research could broaden this investigation beyond the four determinants of PINC behavior considered.
Funding Open Access funding enabled and organized by Projekt DEAL.

\section{Compliance with Ethical Standards}

Conflict of interest The authors declare that they have no conflicts of interest.

Ethical approval The authors declare that they comply with ethical standards.

Research Involving Human Participants All procedures performed in studies involving human participants were in accordance with the ethical standards of the institutional and national research committee and with the 1964 Helsinki declaration and its later amendments or comparable ethical standards.

Open Access This article is licensed under a Creative Commons Attribution 4.0 International License, which permits use, sharing, adaptation, distribution and reproduction in any medium or format, as long as you give appropriate credit to the original author(s) and the source, provide a link to the Creative Commons licence, and indicate if changes were made. The images or other third party material in this article are included in the article's Creative Commons licence, unless indicated otherwise in a credit line to the material. If material is not included in the article's Creative Commons licence and your intended use is not permitted by statutory regulation or exceeds the permitted use, you will need to obtain permission directly from the copyright holder. To view a copy of this licence, visit http://creativecommons.org/licenses/by/4.0/.

\section{Appendix}

\section{Measures Used in the Main Analysis}

Most of the questions are stated as follows:

To what extent do you agree with the following statement?

Answers base on a seven-point Likert-scale with one for strongly disagree and seven for strongly agree, 0 for no information. Exceptions are marked.

[R] Statements are reverse coded. 


\section{Individuals' engagement in PINC (PINC)}

PINC1 Noncompliance with some rules may be allowable for employees with my job

PINC2 Noncompliance with some corporate rules may be allowable for employees with my job if it is the only way to achieve the targets

PINC3 Noncompliance with some corporate rules may be allowable for employees with my job if these are rules imposed by the company itself, i.e., which are not based on legal requirements

PINC4 Noncompliance with some corporate rules may be allowable for employees with my job if the success of the company can be increased

PINC5 Compliance with corporate rules is always more important to me than sales success. [R]

PINC6 Case Study 1:

You are about to close a lucrative deal. Suddenly, it turns out that this deal does not meet the environmental standards of your company. However, the noncompliance with these standards would not be communicated

I would close the lucrative deal

PINC7 Case Study 2:

You are selling a product to a customer. Suddenly, it turns out that the customer does not have the technical infrastructure to exploit the full potential of the product. However, the customer is not aware of this, and will not be informed about it. You might offer the customer an alternative product which is cheaper and more suitable. However, it has a much lower profit margin. Nevertheless, the sales code in place stipulates that no relevant information be withhold from the customer

I would only offer the customer the high-priced product

a 'Lucrative ' means profitable/rewarding/moneymaking and therefore desirable for the individual. It is typically used in a sales setting, e.g., in the context of a "lucrative offer".

\section{Tone at the Top}

\section{Corporate Rules (RULES), Performance Pressure (PRESS)}

INC1 It is sometimes difficult to reconcile incentives form performance-based pay with the compliance of corporate rules

INC2 The targets are hardly achievable

INC3 The targets are hardly achievable if I strictly comply with corporate rules

INC4 I consider the performance-related pressure as high (e.g., due to performance-based pay, targets, performance thresholds, rankings, etc.)

RULES1 Does your company provide a summary of corporate rules, e.g., in the form of a code of conduct? (yes/no/I don't know)

RULES2 I feel well informed about corporate rules

RULES3 My superiors communicated in a credible way that I have to comply with corporate rules

RULES4 My immediate superior does not want to be informed about any violations of corporate rules. [R]

RULES5 My superiors communicated in a convincing manner that compliance with corporate rules is more important than financial success

ACC1 I consider the corporate rules useful

$A C C 2$ I consider the corporate rules appropriate

ACC3 I consider it necessary that internal corporate rules are available on top of legal regulations

ACC4 What do you think is the reason that corporate rules exceeding the legal frame are established? (Establishment of an ethical corporate culture, other reasons)

ACC5 What do you think is the reason that corporate rules exceeding the legal frame are established? (Assuming corporate responsibility, other reasons)

\section{Tone at the Bottom}

PINC Expectations (EXPECT), PINC Behavior (BEHAV)

SUPER1

SUPER2

SUPER4

SUPER5

SUPER6
My superiors comply with corporate rules. [R]

If I strictly comply with corporate rules, it is often difficult for me to fulfil the expectations of my immediate superior

The instructions of my immediate superior are sometimes difficult to reconcile with corporate rules

If I forego a lucrative deal, because this violates certain corporate rules, my immediate superior will praise me for this behavior. [R]

If I forego a lucrative deal, because this violates some corporate rules, my immediate superior will be angry

If I forego a lucrative deal, because this violates some corporate rules, my immediate superior will attribute this to a lack of commitment 


\begin{tabular}{lc}
\hline SUPER7 & My immediate superior tolerates \\
& violations of corporate rules \\
& if they contribute to her/his \\
& personal success \\
& Many of my colleagues have \\
already deviated from corporate & rules \\
COLL1 & Some of my colleagues regularly \\
& deviate from corporate rules \\
\end{tabular}

Individual's Tendency to Harm for the Greater Good (UTIL)

\begin{tabular}{cc}
\hline UTIL1 & $\begin{array}{c}\text { It is morally right to harm an innocent person if } \\
\text { harming them is a necessary means to helping } \\
\text { several other innocent people }\end{array}$ \\
If the only way to ensure the overall well-being \\
and happiness of the people is through the \\
use of political oppression for a short, limited \\
period, then political oppression should be used \\
It is permissible to torture an innocent person if \\
this would be necessary to provide information \\
to prevent a bomb going off that would kill \\
hundreds of people \\
Sometimes it is morally necessary for innocent \\
people to die as collateral damage-if more \\
people are saved overall
\end{tabular}

\section{References}

Anlanger, R., Engel, W. A., Schuster, R. J., \& Weiche, G. (2015). Technischer Vertrieb: Panelstudie 2015. Vienna: University of Applied Sciences of bfi Vienna.

Armstrong, J. S., \& Overton, T. S. (1977). Estimating Nonresponse Bias in Mail Surveys. Journal of Marketing Research, 14(3), 396. https://doi.org/10.2307/3150783

Arnold, M. C., \& Artz, M. (2015). Target difficulty, target flexibility, and firm performance: Evidence from business units' targets. Accounting, Organizations and Society, 40, 61-77. https://doi. org/10.1016/j.aos.2014.12.002

Badrinarayanan, V., Ramachandran, I., \& Madhavaram, S. (2019). Mirroring the boss: Ethical leadership, emulation intentions, and salesperson performance. Journal of Business Ethics, 159(3), 897-912. https://doi.org/10.1007/s10551-018-3842-1

Bandura, A. (1977). Social learning theory (Prentice-Hall series in social learning theory). Englewood Cliffs, New Jersey: Prentice-Hall.

Bandura, A. (1999). Moral disengagement in the perpetration of inhumanities. Personality and Social Psychology Review, 3(3), 193209. https://doi.org/10.1207/s15327957pspr0303_3.

Bandura, A. (2002). Selective moral disengagement in the exercise of moral agency. Journal of Moral Education, 31(2), 101-119. https ://doi.org/10.1080/0305724022014322

Bandura, A., Barbaranelli, C., Caprara, G. V., \& Pastorelli, C. (1996). Mechanisms of moral disengagement in the exercise of moral agency. Journal of Personality and Social Psychology, 71(2), 364-374. https://doi.org/10.1037/0022-3514.71.2.364.
Bannier, C. E., Bauer, A., Bofinger, Y., \& Ewelt-Knauer, C. (2020). The Corporate Compliance Function-Effects on Equity and Credit Risk. Working Paper.

Barsky, A. (2008). Understanding the ethical cost of organizational goal-setting: A review and theory development. Journal of Business Ethics, 81(1), 63-81. https://doi.org/10.1007/s1055 1-007-9481-6

Bergstresser, D., \& Philippon, T. (2006). CEO incentives and earnings management. Journal of Financial Economics, 80(3), 511-529. https://doi.org/10.1016/j.jfineco.2004.10.011

Bersoff, D. M. (1999). Why good people sometimes do bad things: Motivated reasoning and unethical behavior. Personality \& Social Psychology Bulletin, 25(1), 28-39. https://doi. org/10.1177/0146167299025001003

Bicchieri, C., \& Xiao, E. (2009). Do the right thing: But only if others do so. Journal of Behavioral Decision Making, 22(2), 191-208. https://doi.org/10.1002/bdm.621

Chatterjee, S., \& Hadi, A. S. (2015). Regression analysis by example (5th ed., Wiley Series in Probability and Statistics). Wiley, New York

Cialdini, R. B., \& Goldstein, N. J. (2004). Social influence: compliance and conformity. Annual review of psychology, 55, 591621. https://doi.org/10.1146/annurev.psych.55.090902.142015

Cialdini, R. B., \& Trost, M. R. (1998). Social influence: social norms, conformity, and compliance. In D. T. Gilbert, S. T. Fiske, \& G. Lindzey (Eds.), The Handbook of Social Psychology (4th ed., pp. 151-192). Boston: McGraw-Hill.

Cialdini, R. B., Reno, R. R., \& Kallgren, C. A. (1990). A focus theory of normative conduct: Recycling the concept of norms to reduce littering in public places. Journal of Personality and Social Psychology, 58(6), 1015-1026. https://doi. org/10.1037/0022-3514.58.6.1015

Dahling, J. J., Chau, S. L., Mayer, D. M., \& Gregory, J. B. (2012). Breaking rules for the right reasons? An investigation of prosocial rule breaking. Journal of Organizational Behavior, 33(1), 21-42. https://doi.org/10.1002/job.730

Davis, A. L., \& Rothstein, H. R. (2006). The effects of the perceived behavioral integrity of managers on employee attitudes: A metaanalysis. Journal of Business Ethics, 67(4), 407-419. https:// doi.org/10.1007/s10551-006-9034-4

Deloitte. (2019). Studie zur Vertriebsvergütung 2019: Mitarbeiterperspektiven auf den Vertrieb im digitalen Zeitalter (Study on sales compensation 2019: Employee perspectives on sales in the digital age). https://www2.deloitte.com/content/dam/Deloi tte/de/Documents/human-capital/Deloitte-Studie-Vertriebsv erg\%C3\%BCtung-2019.pdf. Accessed 2 July 2020.

Ewelt-Knauer, C., Knauer, T., \& Sharp, D. (2020). The Effect of Relative Performance Information, Peers' Rule-breaking, and Controls on Employees' own Rule-breaking. European Accounting Review, forthcoming.

Felps, W., Mitchell, T. R., \& Byington, E. (2006). How, when, and why bad apples spoil the barrel: Negative group members and dysfunctional groups. Research in Organizational Behavior, 27, 175-222. https://doi.org/10.1016/S0191-3085(06)27005-9

Fleischman, G. M., Johnson, E. N., Walker, K. B., \& Valentine, S. R. (2019). Ethics versus outcomes: Managerial responses to incentive-driven and goal-induced employee behavior. Journal of Business Ethics, 158(4), 951-967. https://doi.org/10.1007/ s10551-017-3695-z

Galbreath, J. (2019). Drivers of green innovations: The impact of export intensity, women leaders, and absorptive capacity. Journal of Business Ethics, 158(1), 47-61. https://doi.org/10.1007/ s10551-017-3715-z

Gorsuch, R. L. (1997). Exploratory factor analysis: Its role in item analysis. Journal of Personality Assessment, 68(3), 532-560. https://doi.org/10.1207/s15327752jpa6803_5 
Green, R. M. (1991). When is "Everyone's Doing It" A Moral Justification? Business Ethics Quarterly, 1(1), 75-93. https://doi. org/10.2307/3857593

Hair, J. F., Black, W. C., Babin, B. J., \& Anderson, R. E. (2019). Multivariate data analysis. Andover, Hampshire: Cengage Learning EMEA.

Kahane, G., Everett, J. A. C., Earp, B. D., Caviola, L., Faber, N. S., Crockett, M. J., \& Savulescu, J. (2018). Beyond sacrificial harm: A two-dimensional model of utilitarian psychology. Psychological Review, 125(2), 131-164. https://doi.org/10.1037/rev0000093

Kaiser, H. F. (1960). The application of electronic computers to factor analysis. Educational and Psychological Measurement(1), $141-151$.

Lord, A. T., \& DeZoort, T. F. (2001). The impact of commitment and moral reasoning on auditors' responses to social influence pressure. Accounting, Organizations and Society, 26(3), 215-235. https://doi.org/10.1016/S0361-3682(00)00022-2

Mahlendorf, M. D., Matějka, M., \& Weber, J. (2018). Determinants of financial managers' willingness to engage in unethical pro-organizational behavior. Journal of Management Accounting Research, 30(2), 81-104. https://doi.org/10.2308/jmar-51957

March, J. G., Schulz, M., \& Zhou, X. (2000). The dynamics of rules: Change in written organizational codes. Stanford, California: Stanford University Press.

Morrison, E. W. (2006). Doing the job well: An investigation of prosocial rule breaking. Journal of Management, 32(1), 5-28. https ://doi.org/10.1177/0149206305277790

O'Brien, R. M. (2007). A caution regarding rules of thumb for variance inflation factors. Quality \& Quantity, 41(5), 673-690. https://doi. org/10.1007/s11135-006-9018-6

Ordóñez, L. D., \& Welsh, D. T. (2015). Immoral goals: How goal setting may lead to unethical behavior. Current Opinion in Psychology, 6, 93-96. https://doi.org/10.1016/j.copsyc.2015.06.001

Pickerd, J. S., Summers, S. L., \& Wood, D. A. (2015). An examination of how entry-level staff auditors respond to tone at the top vis-àvis tone at the bottom. Behavioral Research in Accounting, 27(1), 79-98. https://doi.org/10.2308/bria-50918

Román, S., \& Ruiz, S. (2005). Relationship outcomes of perceived ethical sales behavior: The customer's perspective. Journal of Business Research, 58(4), 439-445. https://doi.org/10.1016/j. jbusres.2003.07.002

Román, S., Rodríguez, R., \& Jaramillo, J. F. (2018). Are mobile devices a blessing or a curse? Effects of mobile technology use on salesperson role stress and job satisfaction. Journal of Business \& Industrial Marketing, 33(5), 651-664. https://doi.org/10.1108/ JBIM-05-2017-0123

Ross, W. T., \& Robertsin, D. C. (2003). A typology of situational factors: Impact on salesperson decision-making about ethical issues. Journal of Business Ethics, 46(3), 213-234.

Schaubroeck, J. M., Hannah, S. T., Avolio, B. J., Kozlowski, S. W. J., Lord, R. G., Treviño, L. K., et al. (2012). Embedding ethical leadership within and across organization levels. Academy of Management Journal, 55(5), 1053-1078. https://doi.org/10.5465/ amj.2011.0064

Schmitz, C. (2013). Group influences of selling teams on industrial salespeople's cross-selling behavior. Journal of the Academy of Marketing Science, 41(1), 55-72. https://doi.org/10.1007/s1174 7-012-0304-7

Serviere-Munoz, L., \& Mallin, M. L. (2013). How do unethical salespeople sleep at night?: The role of neutralizations in the justification of unethical sales intentions. Journal of Personal Selling \& Sales Management, 33(3), 289-306. https://doi. org/10.2753/PSS0885-3134330304

Sims, R. R., \& Brinkmann, J. (2003). Enron ethics (Or: Culture matters more than codes). Journal of Business Ethics, 45(3), 243-256.

Spector, P. E. (1992). Summated rating scale construction: An introduction (Sage University papers Quantitative applications in the social sciences, Vol. 82). Sage, Newbury Park, California.

Stevens, B. (2008). Corporate ethical codes: Effective instruments for influencing behavior. Journal of Business Ethics, 78(4), 601-609. https://doi.org/10.1007/s10551-007-9370-z

Tabachnick, B. G., \& Fidell, L. S. (2014). Using multivariate statistics (6th ed., Pearson custom library). Pearson Education, Harlow, Essex.

Tepper, B. J. (2010). When managers pressure employees to behave badly: Toward a comprehensive response. Business Horizons, 53(6), 591-598. https://doi.org/10.1016/j.bushor.2010.07.002

Tyler, T. R., \& Blader, S. L. (2005). Can businesses effectively regulate employee conduct? The antecedents of rule following in work settings. Academy of Management Journal, 48(6), 1143-1158. https ://doi.org/10.5465/AMJ.2005.19573114

Umphress, E. E., \& Bingham, J. B. (2011). When employees do bad things for good reasons: Examining unethical pro-organizational behaviors. Organization Science, 22(3), 621-640. https://doi. org/10.1287/orsc. 1100.0559

Umphress, E. E., Bingham, J. B., \& Mitchell, M. S. (2010). Unethical behavior in the name of the company: The moderating effect of organizational identification and positive reciprocity beliefs on unethical pro-organizational behavior. The Journal of Applied Psychology, 95(4), 769-780. https://doi.org/10.1037/a0019214

Warren, D. E., Peytcheva, M., \& Gaspar, J. P. (2015). When ethical tones at the top conflict: Adapting priority rules to reconcile conflicting tones. Business Ethics Quarterly, 25(4), 559-582. https:// doi.org/10.1017/beq.2015.40

Weaver, G. R., \& Treviño, L. K. (1999). Compliance and values oriented ethics programs. Business Ethics Quarterly, 9(2), 315-335. https://doi.org/10.5840/10.2307/3857477

Weaver, G. R., Treviño, L. K., \& Cochran, P. L. (1999). Corporate ethics programs as control systems: Influences of executive commitment and environmental factors. Academy of Management Journal, 42(1), 41-57. https://doi.org/10.5465/256873

Weber, J., \& Wasieleski, D. M. (2013). Corporate ethics and compliance programs: A report, analysis and critique. Journal of Business Ethics, 112(4), 609-626. https://doi.org/10.1007/s1055 1-012-1561-6

Welsh, D., Bush, J., Thiel, C., \& Bonner, J. (2019). Reconceptualizing goal setting's dark side: The ethical consequences of learning versus outcome goals. Organizational Behavior and Human Decision Processes, 150, 14-27. https://doi.org/10.1016/j.obhdp .2018.11.001

Welsh, D. T., \& Ordóñez, L. D. (2014). Conscience without cognition: The effects of subconscious priming on ethical behavior. Academy of Management Journal, 57(3), 723-742. https://doi.org/10.5465/ amj.2011.1009

Publisher's Note Springer Nature remains neutral with regard to jurisdictional claims in published maps and institutional affiliations. 